\title{
Effect of White Willow Bark on Delayed Onset Muscle Soreness Following Resistance Training: A Pilot Study
}

\author{
Brandie Cai Cheshier ${ }^{1 *}$, Bert Hans Jacobson ${ }^{1}$, Cody Diehl ${ }^{1}$ \\ ${ }^{1}$ School of Kinesiology, Applied Health and Recreation, Oklahoma State University, Stillwater Oklahoma, USA
}

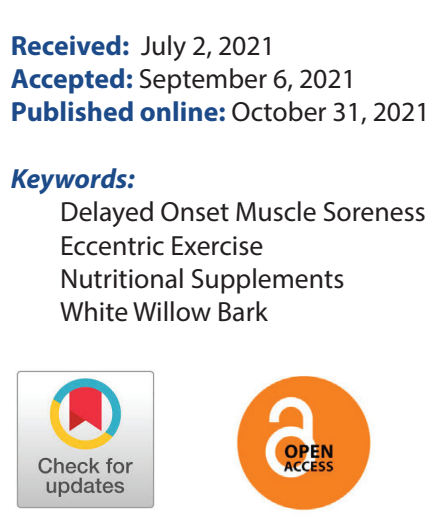

\section{ABSTRACT}

\begin{abstract}
OBJECTIVES Delayed onset muscle soreness (DOMS) is discomfort that occurs within 8-24hrs following an unaccustomed bout of physical activity that peaks within $24-27 \mathrm{hrs}$ and slowly resolves on its own. White willow bark (WWB) is a nutritional supplement that is believed to have anti-inflammatory and analgesic properties like aspirin but without the risk of $\mathrm{Gl}$ adverse effects. The purpose of this investigation is to determine the effectiveness of WWB on alleviating the symptoms of DOMS following exercise.

METHODS Twenty-five individuals volunteered to participate and were randomly assigned to take WWB (798mg salicin) or placebo for 5 days following a lower body resistance training session which consisted of $5 \mathrm{X} 10$ lunges at $40 \%$ body weight (BW) and $3 \mathrm{X}$ fatigue leg press at $75 \% \mathrm{BW}$. Test procedures included visual analog scale (VAS), mid-thigh circumference and pressure pain threshold. VAS was measured pre, all five days of the supplementation period and day 6 (post-supplementation). All other variables were measured at pre, immediate, day $3(72 \mathrm{hrs})$, and day 6 (post-supplementation).

RESULTS No condition X time interaction was observed $(p>0.05)$ for any variable. However, VAS scores were lower in the WWB compared to the placebo for all time frames. There was a significant main effect of time for VAS scores indicating muscle soreness for hamstrings ( $p<0.001)$, gluteal $(p<0.001)$, gastrocnemius ( $p$ $<0.001)$ and quadriceps $(p<0.001)$. In addition, there was a significant main effect of time for right midthigh pressure pain threshold $(p=0.02)$, mid-right $(p<0.001)$ and mid-left $(p<0.001)$ thigh circumference. CONCLUSIONS WWB may reduce subjective feelings of muscle soreness and appears to have analgesic properties.
\end{abstract}

(C) The Asian Society of Kinesiology and the Korean Academy of Kinesiology

\section{Introduction}

Delayed onset muscle soreness (DOMS) is defined as pain or discomfort that occurs after an unaccustomed or highintensity bout of physical activity [1]. Individuals of all fitness levels can experience DOMS following exercise. Following an extensive training session, DOMS typically occurs within 8-24 hours and peaks within 24-72 hours following exercise [2,3]. DOMS resolves on its own within 5-7 days $[2,3]$. The duration

*Correspondence: Brandie Cheshier, School of Kinesiology, Applied Health and Recreation, Oklahoma State University, 101 Colvin Ctr, Stillwater, Oklahoma, USA: Tel: 214-801-0236; E-mail: brandie.cheshier@okstate.edu for healing is dependent on the severity of the muscle damage and fitness level of the individual $[1,4]$. Eccentric exercise is well documented as the culprit of DOMS [5]. Any exercise that contains an eccentric component (plyometric exercise, squatting, jumping, downhill running, and the lowering phase of resistance training) will produce muscle fiber damage, inflammation, DOMS, and muscle function deficits [6]. The sensation of pain can deter an individual from adhering to an exercise program, interfere with activities of daily living, and decrease athletic performance [3].

Recently, there has been an increased interest in 
nutritional supplements and their ability to alleviate pain and inflammation associated with DOMS. An herbal supplement that may offset the adverse effects of DOMS is willow bark. Willow bark (Salix alba L.) is obtained from the whole or fragmented dried bark of young (2-3 years old) branches or twigs from various species of Salix, belonging to the Salicaceae family [7]. Historical records show that willow bark has been used for thousands of years in ancient China, Egypt, Greece, and South Asia to alleviate headaches, fever, pain and treat numerous other illnesses [8]. The discovery of the pharmacological active ingredient salicin and its constitute salicylic acid in the 1800 s paved the way for chemists to synthetically produce the acetylated derivative of salicylic acid into the most popular drug world wide, Aspirin [7,9]. Today, willow bark is often refereed as the herbal counterpart of Aspirin with similar analgesic and anti-inflammatory properties with a lower risk of experiencing gastrointestinal upset.

Currently, there is no uniform recommended dosage for willow bark extract. The European Medicine Agency (EMA) suggest a dose of 393-1572mg extract corresponding to no more than 240mg salicin per day [10]. In addition to salicin, willow bark is shown to contain high levels of polyphenols (salicylates, flavonoids, proanthocyanidins, and tannins) that contribute to its overall analgesic and anti-inflammatory effects. The exact mechanism willow bark acts upon to produce both anti-inflammatory and analgesic effects is not agreed upon. It is theorized that willow bark has inhibitory actions on the arachidonic acid pathway. More specifically, willow bark may target COX-1 and COX-2, to decrease pain and inflammation.

To date, the effects of willow bark on pain and inflammation has been studied in individuals with osteoarthritis [11,12] chronic low back pain [13-16] and rheumatic pain with results showing a potential for willow bark in alleviating pain and inflammation [11, 16-18]. To our knowledge, no studies have been conducted on the potential of willow bark in alleviating pain and inflammation in a non-clinical population. The aim of this pilot study was to investigate the effectiveness of white willow bark (WWB) on alleviating pain and inflammation associated with DOMS in healthy collage age individuals following an exhaustive lower body resistance training session.

\section{Methods}

\section{Participants}

Twenty-five participants volunteered for this investigation. All participants were required to be healthy and free from any signs or symptoms of disease, musculoskeletal injury, free from arthritis (i.e., osteoarthritis, gout, rheumatoid arthritis), or have chronic back pain. Furthermore, participants were asked to refrain from taking any NSAIDs, analgesics, corticosteroids, or any type of nutritional aid that could interfere with the potential therapeutic actions of WWB. Those who were taking medication known to interfere with WWB (i.e., anticoagulants, beta blockers, diuretic, methotrexate, or phenytoin) and those with a known allergy or sensitivity to salicylates such as aspirin were excluded from this investigation. Each participant was randomly placed in either the WWB group $(n=11)$ or placebo group $(n=14)$ using a computerized randomized scheme. This study was approved by Oklahoma State University IRB for human participant research (IRB-20-44-STW).

\section{Study Design}

The study was designed as a double-blind randomized control trial to compare the effects of taking oral WWB to a placebo on parameters of DOMS such as pain and inflammation following an exhaustive lower body resistance training session. The current investigation included four visits to the lab and five days of supplementation. Session one consisted of equipment familiarization, height, weight, and the competition of pre-participation paperwork. During session two, baseline parameters of DOMS (muscle soreness, mid-thigh circumference, and pressure pain threshold) were measured. After the collection of baseline data, participants took part in a lower body resistance training session to induce DOMS. After the completion of the training session and resting for 10 minutes, the parameters of DOMS were measured again. Beginning the morning after session two, participants began the five day supplementation period. Participants were required to report back to the lab on day three (72 hrs.) and day 6 (post-supplementation). All testing 
procedures were performed at a consistent time each session.

\section{Treatment Conditions}

Immediately following the collection of the immediate response measurements, participants ingested their first dose (two capsules) of WWB or placebo with water. Beginning the morning after session two, participants began the five day supplementation period. During the supplementation period, participants in the WWB group took two capsules containing $133 \mathrm{mg}$ of willow bark extract three times daily for a total of $798 \mathrm{mg}$ per day [19]. The placebo group took two capsules containing powder sugar three times daily. Participants in both treatment conditions were instructed to ingest two capsules each morning, noon, and night with a meal for five days.

\section{DOMS- Induced Protocol}

Following the collection of baseline data, participants took part in a lower body resistance training session to induce DOMS. After a five minute warm up on a cycle ergometer, participants first performed five sets of 10 lunges at $40 \%$ of their body weight with a one minute rest between sets. Following the completion of lunges, participants completed three sets to fatigue on the seated leg press (Hammer Strength Select Seated Leg Press; Life Fitness Inc, Park, IL, USA) at 75\% of their body weight with a one minute rest between each set. To standardize the protocol during the leg press, a metronome (Metronome app by ONYX Apps; Apple Inc, Cupertino, CA) was set at 60 beats per minute [20]. Fatigue was determined when participants could no longer lift the weight or could no longer keep up with the metronome on three consecutive counts.

\section{Outcome Measures}

DOMS

A $100 \mathrm{~mm}$ visual analog scale (VAS) was used to measure subjective pain and discomfort for the hamstrings, quadriceps, gastrocnemius, and gluteal muscles. Baseline VAS was measured during session two before participants completed the lower body resistance training session to induce DOMS. Following the induction of DOMS, participants were sent home with a five day VAS packet. Each day during the supplementation period, participants rated their level of pain or discomfort for the quadriceps, hamstrings, gastrocnemius, and gluteal muscles each morning within 30 minutes of waking. On day six, (post- supplementation), participants brought their VAS packet to their last session to turn in to the primary investigator for analysis and to complete their final (post supplementation) VAS.

A handheld algometer (Wagner Force Ten ${ }^{\mathrm{TM}}$ Digital Force Gage; Wagner Instruments, Greenwich, CT, USA) was used to measure pressure pain threshold. A handheld algometer has been shown to be a valid and reliable tool in evaluating pressure pain threshold $[21,22]$. Participants were asked to place one foot on a chair, so both the knee and hip were at $90^{\circ}$ measured by a goniometer. Using a Gulick tape measure, the midpoint between the inguinal crease and the proximal border of the patella was measured. Using a semi-permanent marker, a small dot was placed at the midpoint where pressure pain threshold was to be measured. The handheld algometer was placed on the dot. Participants were asked to report when "pressure began to feel uncomfortable." Pressure was applied in a slow downward manner and at the participants response of "stop," the measurement was recorded to the nearest $0.01 \mathrm{oz}$. The average of three measurements were obtained for both right and left mid-thighs while alternating thighs after each measurement. Pressure pain threshold was measured at baseline, immediate response, day three (72 hrs.) and day six (post-supplementation).

\section{Inflammation}

To access inflammation, a mid-thigh circumference was utilized for both right and left mid-thigh. Using the same spot where pressure pain threshold was measured (the midpoint between the inguinal crease and the proximal border of the patella), three measurements were obtained, and the average was recorded. This was completed for both right and left midthigh. Mid-thigh circumference was measured at baseline, immediately following exercise, day three (72hrs.) and day six (post-supplementation).

\section{Statistical Analysis}

All results are expressed as mean \pm standard deviation (SD) and statistical significance was set a $p<0.05$. Using SPSS 
statistical software (Version 27.0, IBM Corp, Chicago, IL, USA), two-way repeated measures ANOVAs were conducted for the following variables, VAS quadriceps, VAS hamstrings, VAS gastrocnemius, VAS gluteal muscles, right and left mid- thigh circumference and right and left thigh pressure pain threshold. Mauchley's test was applied to evaluate the assumption of sphericity for repeated measures ANOVA. If the assumption of sphericity was violated, the Greenhouse-Geisser was used. The main effects were analyzed for all variables that showed no significant interaction effects. For a significant main effect, all pairwise comparisons were examined with a Bonferroni correction. Cohen's d was calculated to determine effect size $(d)$ treatment conditions and interpreted as 0.2 , 0.5 and 0.8 for small, medium, and large effects. Participant demographics were compared using an independent-t test.

\section{Results}

The characteristics of the participants are presented in $<$ Table $1>$. Twenty-five healthy males $(\mathrm{n}=10)$ and females $(\mathrm{n}=15)$ took part in this investigation. Fourteen were randomly placed in the placebo group (male: 6; female: 8 ) and 11 in the WWB (male: 4; female: 7) group. The results of the independent t-test revealed no significant differences $(p>$ 0.05 ) between the groups in age, height, weight, and body mass index (BMI). All 25 participants reported no adverse effects during the investigation.

Table 1. Demographic Data

\begin{tabular}{llll}
\hline & Placebo $(\mathbf{n}=14)$ & WWB $(\mathbf{n = 1 1 )}$ & $\boldsymbol{p}$ - value \\
\hline Age $(\mathrm{yrs})$. & $19.93 \pm 10.29$ & $20.37 \pm 1.29$ & 0.316 \\
Height $(\mathrm{cm})$ & $170.91 \pm 10.29$ & $168.97 \pm 10.22$ & 0.643 \\
Weight $(\mathrm{kg})$ & $74.54 \pm 17.51$ & $72.86 \pm 12.30$ & 0.787 \\
BMI $\left(\mathrm{kg} / \mathrm{m}^{2}\right)$ & $25.35 \pm 5.37$ & $25.57 \pm 4.75$ & 0.918 \\
\hline
\end{tabular}

Mean $\pm \mathrm{SD}$; yrs.: years; $\mathrm{cm}$ : centimeters; $\mathrm{kg}$ : kilograms; $\mathrm{kg} / \mathrm{m}^{2}$ kilogram per meter squared; WWB: white willow bark; BMI: body mass index

\section{DOMS}

VAS scores for both groups are presented in $<$ Table $2>$. No significant differences between the groups for hamstring, quadricep, gastrocnemius, or gluteal muscle soreness $(p>$
0.05) was observed. When collapsed across the groups, there was a significant main effect of time for hamstring, quadricep, gastrocnemius, or gluteal muscle soreness $(p<0.05)$. In all time frames, except for day-five for the gastrocnemius muscle, the rating of muscle soreness or discomfort was lower than that of the placebo. During the peak (approximately 48hrs following exercise) of gluteal muscle soreness, the placebo group rating of muscle soreness or discomfort was $21.53 \%$ higher than the WWB group $(77.18 \pm 17.82 \mathrm{~mm} ; 60.56 \pm$ $26.88 \mathrm{~mm}$, respectively). In both groups, hamstring muscle soreness peaked within $24 \mathrm{hrs}$ of exercise and the placebo group was $28.35 \%$ more sore than those in the WWB group $(44.80 \pm 26.96 \mathrm{~mm} ; 32.10 \pm 28.81 \mathrm{~mm}$ respectively). Peak soreness for the quadriceps in both groups occurred on day three (72 hours) following resistance training. While not statistically significant, the WWB group rated their muscle soreness $22.53 \%$ lower than the placebo $(53.40 \pm 31.43 \mathrm{~mm}$; $68.93 \pm 27.51 \mathrm{~mm}$ respectively).

No significant difference between the conditions for both right and left mid-thigh pressure pain threshold $(p>0.05)$ $<$ Table $3>$. However, there was a significant main effect of time for the right mid-thigh $(p=0.02)$. In comparison, there was no significant main effect of time for the pressure pain threshold for the left mid-thigh ( $p=0.207)$. In the WWB group, $72 \mathrm{hrs}$ after exercise, both right and left mid-thigh pressure pain threshold was lower than what it was at baseline $(3.05 \%$ and $3.69 \%$ respectively). In comparison, in the placebo group, right mid-thigh pressure pain threshold was $13.76 \%$ lower than baseline and the left mid-thigh was $10.03 \%$ lower than baseline. When collapsed across groups, there was a significant $(p<0.05)$ time difference for right mid-thigh pressure pain threshold on day three (72hrs) following resistance training. Quadriceps muscle soreness peaked on day three (72 hrs.) following exercise. This corresponds with the significant decrease in pressure pain threshold observed on day three (72 hrs.) for right mid-thigh. The pressure pain threshold for day three in the placebo group was 5.20\% and $10.03 \%$ lower than the baseline measurements for the right and left mid-thigh, respectively. 
Table 2. VAS for Hamstring, Gluteal, Gastrocnemius, Quadriceps Muscles*

\begin{tabular}{|c|c|c|c|c|c|c|c|}
\hline \multicolumn{8}{|c|}{ Hamstrings } \\
\hline & Baseline $^{\text {bcd }}$ & Day $1^{\text {aefg }}$ & Day $2^{\text {aefg }}$ & Day $3^{\text {aefg }}$ & Day $4^{\text {abfg }}$ & Day $5^{\text {bcd }}$ & Post $^{\text {bcd }}$ \\
\hline Placebo & $0.45 \pm 0.50$ & $44.80 \pm 26.96$ & $44.30 \pm 29.68$ & $27.30 \pm 24.40$ & $8.20 \pm 9.14$ & $1.95 \pm 3.07$ & $1.35 \pm 1.23$ \\
\hline \% Diff Prev. Day & & $9855.56 \%$ & $-1.12 \%$ & $-38.37 \%$ & $-69.96 \%$ & $-76.22 \%$ & $-30.77 \%$ \\
\hline WWB & $0.10 \pm .32$ & $32.10 \pm 28.61$ & $30.11 \pm 35.04$ & $16.02 \pm 20.24$ & $3.20 \pm 9.14$ & $0.70 \pm 1.16$ & $0.50 \pm 1.27$ \\
\hline \% Diff Prev. Day & & $3200.00 \%$ & $-6.20 \%$ & $-46.80 \%$ & $-80.02 \%$ & $-78.13 \%$ & $-28.57 \%$ \\
\hline Difference (mm) & 0.35 & 12.70 & 14.19 & 11.28 & 5.0 & 1.25 & 0.85 \\
\hline Effect Size (d) & .83 & 0.45 & 0.44 & 0.50 & 0.55 & 0.54 & 0.68 \\
\hline \multicolumn{8}{|c|}{ Gluteal } \\
\hline & Baseline bcde $^{\text {bc }}$ & Day $1^{\text {adefg }}$ & Day $2^{\text {adefg }}$ & Day $3^{\text {abcefg }}$ & Day $4^{\text {abcdfg }}$ & Day $5^{\text {bcde }}$ & Post ${ }^{\text {bcde }}$ \\
\hline Placebo & $0.41 \pm 0.49$ & $77.18 \pm 13.66$ & $77.18 \pm 17.82$ & $46.18 \pm 26.47$ & $15.91 \pm 16.90$ & $7.95 \pm 11.77$ & $1.91 \pm 4.75$ \\
\hline \% Diff Prev. Day & & $18724.39 \%$ & $0.00 \%$ & $-40.17 \%$ & $-65.55 \%$ & $-50.03 \%$ & $-75.97 \%$ \\
\hline WWB & $0.11 \pm 0.33$ & $59.22 \pm 28.27$ & $60.56 \pm 26.88$ & $26.11 \pm 21.50$ & $9.17 \pm 13.70$ & $3.11 \pm 5.4$ & $1.50 \pm 2.47$ \\
\hline \% Diff Prev. Day & & $53736.36 \%$ & $2.26 \%$ & $-56.89 \%$ & $-64.88 \%$ & $-66.09 \%$ & $-51.77 \%$ \\
\hline Difference (mm) & 0.30 & 17.96 & 16.62 & 20.07 & 6.74 & 4.84 & 0.41 \\
\hline Effect Size (d) & .72 & 0.81 & 0.73 & 0.83 & 0.44 & 0.53 & 0.11 \\
\hline \multicolumn{8}{|c|}{ Gastrocnemius } \\
\hline & Baseline $^{b}$ & Day $1^{\text {aefg }}$ & Day 2 & Day 3 & Day $4^{b}$ & Day $5^{b}$ & Post $^{b}$ \\
\hline Placebo & $0.30 \pm 0.35$ & $10.60 \pm 10.00$ & $7.30 \pm 9.34$ & $3.50 \pm 5.25$ & $1.05 \pm 2.48$ & $0.15 \pm 0.34$ & $0.80 \pm 1.11$ \\
\hline \% Diff Prev. Day & & $3433.33 \%$ & $-31.13 \%$ & $-52.05 \%$ & $-70.00 \%$ & $-85.71 \%$ & $81.25 \%$ \\
\hline WWB & $0.09 \pm 0.30$ & $6.82 \pm 9.18$ & $2.93 \pm 4.02$ & $1.74 \pm 3.43$ & $.46 \pm 1.21$ & $0.73 \pm 1.10$ & $0.45 \pm 1.11$ \\
\hline \% Diff Prev. Day & & $7477.78 \%$ & $-57.04 \%$ & $-40.61 \%$ & $-73.56 \%$ & $58.70 \%$ & $-38.36 \%$ \\
\hline Difference (mm) & .21 & 3.78 & 10.04 & 4.37 & .59 & .58 & .35 \\
\hline Effect Size (d) & 0.64 & 0.39 & 0.61 & 0.40 & 0.30 & 0.71 & 0.31 \\
\hline \multicolumn{8}{|c|}{ Quadriceps } \\
\hline & Baseline $e^{\text {bcedf }}$ & Day $1^{\text {cdef }}$ & Day $2^{\text {abfg }}$ & Day $3^{\text {abefg }}$ & Day $4^{\text {abfg }}$ & Day $5^{\text {abcdeg }}$ & Post $^{\text {acdef }}$ \\
\hline Placebo & $0.88 \pm 1.17$ & $3.73 \pm 5.54$ & $63.08 \pm 24.79$ & $68.93 \pm 27.51$ & $51.38 \pm 25.01$ & $23.69 \pm 21.41$ & $9.02 \pm 10.84$ \\
\hline \% Diff Prev. Day & & $323.86 \%$ & $1591.15 \%$ & $9.27 \%$ & $-25.46 \%$ & $-53.89 \%$ & $-61.92 \%$ \\
\hline WWB & $0.10 \pm 0.54$ & $2.31 \pm 3.58$ & $44.70 \pm 33.60$ & $53.40 \pm 31.43$ & $47.30 \pm 24.73$ & $20.80 \pm 21.41$ & $7.50 \pm 8.41$ \\
\hline \% Diff Prev. Day & & $221.00 \%$ & $1835.06 \%$ & $19.46 \%$ & $-11.42 \%$ & $-56.03 \%$ & $-63.94 \%$ \\
\hline Difference (mm) & 0.78 & 2.31 & 18.38 & 15.53 & 4.08 & 2.89 & 1.52 \\
\hline Effect Size (d) & 0.86 & 0.30 & 0.62 & 0.53 & 0.16 & 0.11 & 0.16 \\
\hline $\begin{array}{l}\text { Mean } \pm S D ;{ }^{*} \text { sigr } \\
\text { a: a significant tin } \\
\text { b: a significant tir } \\
\text { c: a significant tin } \\
\text { d: a significant tir } \\
\text { e: a significant tin }\end{array}$ & $\begin{array}{l}\text { nt main effect } \\
\text { fference from b } \\
\text { fference from c } \\
\text { fference from d } \\
\text { fference from } c \\
\text { fference from } c\end{array}$ & $\begin{array}{l}\text { me (collapsed } \\
\text { line } \\
1 \\
2 \\
3\end{array}$ & groups) (p & WWB: whit & w bark; $\mathrm{mm}$ & eters. & \\
\hline
\end{tabular}

\section{Inflammation}

No significant difference between the conditions for both the left and right mid-thigh circumference $(p>0.05)<$ Table $3>$. When collapsed across groups, there was a significant main effect of time for both the right $(p<0.001)$ and left $(p<0.001)$ mid-thighs. Peak thigh circumference occurred immediately following exercise and was significantly higher than the baseline value. 
Table 3. Parameters of Muscle Damage Measured Prior and Following DOMS

\begin{tabular}{|c|c|c|c|c|}
\hline \multicolumn{2}{|c|}{ Right Thigh Circumference $(\mathrm{cm})^{*}$} & \multirow{2}{*}{$\begin{array}{l}\text { Placebo } \\
52.58 \pm 5.25\end{array}$} & \multirow{2}{*}{$\begin{array}{l}\text { WWB } \\
52.53 \pm 4.26\end{array}$} & \multirow{2}{*}{$\begin{array}{c}\text { Effect Size (d) Between Conditions } \\
0.01\end{array}$} \\
\hline Baseline $^{b}$ & Mean & & & \\
\hline Immediate ${ }^{\mathrm{ad}}$ & $\begin{array}{l}\text { Mean } \\
\text { \% diff pre }\end{array}$ & $\begin{array}{l}53.51 \pm 5.40 \\
1.77 \%\end{array}$ & $\begin{array}{l}53.36 \pm 3.99 \\
1.58 \%\end{array}$ & 0.03 \\
\hline Day 3 & $\begin{array}{l}\text { Mean } \\
\text { \% diff pre }\end{array}$ & $\begin{array}{l}52.76 \pm 5.26 \\
0.34 \%\end{array}$ & $\begin{array}{l}53.14 \pm 4.55 \\
1.16 \%\end{array}$ & 0.08 \\
\hline Post $^{\mathrm{b}}$ & $\begin{array}{l}\text { Mean } \\
\text { \% diff pre }\end{array}$ & $\begin{array}{l}52.50 \pm 5.30 \\
0.15 \%\end{array}$ & $\begin{array}{l}52.67 \pm 4.43 \\
0.27 \%\end{array}$ & 0.03 \\
\hline \multicolumn{5}{|c|}{ Left Thigh Circumference $(\mathrm{cm})^{*}$} \\
\hline Baseline $^{b}$ & Mean & $52.89 \pm 5.42$ & $52.53 \pm 4.43$ & 0.03 \\
\hline Immediate ${ }^{\text {acd }}$ & $\begin{array}{l}\text { Mean } \\
\text { \% diff pre }\end{array}$ & $\begin{array}{l}54.07 \pm 5.78 \\
2.23 \%\end{array}$ & $\begin{array}{l}53.41 \pm 3.89 \\
1.68 \%\end{array}$ & 0.13 \\
\hline Day $3^{\text {b }}$ & $\begin{array}{l}\text { Mean } \\
\text { \% diff pre }\end{array}$ & $\begin{array}{l}53.17 \pm 5.30 \\
1.89 \%\end{array}$ & $\begin{array}{l}53.01 \pm 4.18 \\
0.91 \%\end{array}$ & 0.03 \\
\hline Post $^{b}$ & $\begin{array}{l}\text { Mean } \\
\text { \% diff pre }\end{array}$ & $\begin{array}{l}52.93 \pm 5.97 \\
0.08 \%\end{array}$ & $\begin{array}{l}52.50 \pm 4.32 \\
-0.06 \%\end{array}$ & 0.08 \\
\hline \multicolumn{5}{|c|}{ Right Pressure Threshold(oz)* } \\
\hline Baseline & Mean & $187.61 \pm 35.68$ & $204.30 \pm 46.94$ & 0.40 \\
\hline Immediate & $\begin{array}{l}\text { Mean } \\
\text { \% diff pre }\end{array}$ & $\begin{array}{l}177.86 \pm 51.28 \\
-5.20 \%\end{array}$ & $\begin{array}{l}198.07 \pm 50.96 \\
-3.05 \%\end{array}$ & 0.40 \\
\hline Day $3^{d}$ & $\begin{array}{l}\text { Mean } \\
\text { \% diff pre }\end{array}$ & $\begin{array}{l}161.79 \pm 44.50 \\
-13.76 \%\end{array}$ & $\begin{array}{l}200.81 \pm 44.59 \\
-1.71 \%\end{array}$ & 0.88 \\
\hline Post $^{c}$ & $\begin{array}{l}\text { Mean } \\
\text { \% diff pre }\end{array}$ & $\begin{array}{l}196.69 \pm 45.89 \\
4.84 \%\end{array}$ & $\begin{array}{l}216.07 \pm 60.31 \\
5.76 \%\end{array}$ & 0.36 \\
\hline \multicolumn{5}{|c|}{ Left Pressure Threshold (oz) } \\
\hline Baseline & Mean & $188.40 \pm 37.41$ & $212.46 \pm 27.08$ & 0.73 \\
\hline Immediate & $\begin{array}{l}\text { Mean } \\
\text { \% diff pre }\end{array}$ & $\begin{array}{l}180.56 \pm 30.09 \\
-4.16 \%\end{array}$ & $\begin{array}{l}213.54 \pm 42.15 \\
0.51 \%\end{array}$ & 0.90 \\
\hline Day 3 & $\begin{array}{l}\text { Mean } \\
\text { \% diff pre }\end{array}$ & $\begin{array}{l}169.51 \pm 53.38 \\
-10.03 \%\end{array}$ & $\begin{array}{l}204.63 \pm 35.16 \\
-3.69 \%\end{array}$ & 0.78 \\
\hline Post & $\begin{array}{l}\text { Mean } \\
\% \text { diff pre }\end{array}$ & $\begin{array}{l}197.27 \pm 45.03 \\
4.71 \%\end{array}$ & $\begin{array}{l}209.67 \pm 27.71 \\
-1.31 \%\end{array}$ & 0.33 \\
\hline
\end{tabular}

Mean $\pm S D$; * significant main effect of time (collapsed across groups) $(p<0.05)$; WWB: white willow bark; sec: seconds; oz:: ounces.

a: a significant time difference from baseline

b: a significant time difference from immediate

c: a significant time difference from day 3

$\mathrm{d}$ : a significant time difference from post

\section{Discussion}

To the best of our knowledge, this was the first investigation to examine the effects of WWB on the parameters of DOMS, as well as the potential of WWB to decrease both pain and inflammation following exercise in healthy adults. Despite not being statistically significant, WWB decreased subjective pain and soreness evaluated by the VAS and preserved pressure pain threshold more than the placebo. For the daily measurements during the five-day supplementation period, those in the WWB group rated their muscle discomfort lower than the placebo with a pronounced lower VAS rating for muscle soreness or discomfort 24-72hrs following exercise. The tendency of WWB being superior to placebo in decreasing subjective muscle soreness is in agreement with other studies that examined the effectiveness of willow bark on decreasing pain [11-13]. Biegert et al. [11] found that willow bark decreased joint pain more than the placebo after six weeks of treatment (15\% vs. $4 \%$ respectively). Schmidt et al. [12] found after two weeks of consuming $240 \mathrm{mg}$ of salicin, osteoarthritis 
pain was decreased by $14 \%$ while those in the placebo group had a $2 \%$ increase in pain. Churbaskik et al. [13] concluded that WWB with a salicin content ranging from 120-240mg provided significantly more pain reduction than placebo. However, caution should be warranted with interpreting the results since participants were allowed to take tramadol as a rescue medication.

Using a VAS to rate individual soreness is shown to be reliable and is used in previous investigations regarding DOMS and pain $[23,24]$. The subjective nature of these scales should be discussed. The ability to deal with pain and discomfort will vary among individuals and may be influenced by their current and past training experiences. Dealing with pain or discomfort is reflected to the individuals' pain threshold and their ability to cope with both the mental and physical manifestations of pain (pain tolerance) [25]. While there is no difference in pain threshold in athletes and no-athletes, athletes have a superior pain tolerance over non-athletes [26]. While the exact mechanism leading to an athletes' superior pain tolerance is not known, it is suggested that both current and past athletes have developed superior cognitive coping strategies to redirect their focus from the pain (dissociation) or focus on the pain to reinterpret it (association) $[25,26]$. While none of the participants were actively taking part in a lower body resistance training program at the time of the study, their past training history may have influenced their perceived muscle soreness and discomfort. Those accustomed to the feeling of DOMS may have rated this perceived muscle soreness or discomfort as minimal compared to those with less experience of DOMS, or with a lesser cognitive coping strategy.

The placebo effect may have influenced the ratings of subjective muscle discomfort or pain following DOMS. The placebo effect is a powerful phenomenal aspect that can influence the physiological mechanisms and outcomes of pain [27]. In an investigation by Carvalho et al. [28], patients suffering from chronic low back pain were given an open label placebo prescription to take with their treatment as usual. At the end of the three week study, patients taking the label placebo prescription experienced significant $(p<$ $0.05)$ pain relief and a decrease in back pain-related disability more than those who continued their treatment as usual. The consumption of a possible analgesic medication along with an expectation of the medication is providing possible relief can lead to an analgesic response [29]. In this investigation, $60 \%$ of participants, regardless of group, believed they had the WWB and $40 \%$ of the participants believed they had the placebo. When the data was broken down into individual treatment groups, $25 \%$ of those in the placebo believed they had the WWB and $36 \%$ in the WWB correctly guessed they had WWB. The participants belief that they were consuming $\mathrm{WWB}$, regardless of grouping, may resulted in a lower pain rating due to their belief that the supplement or placebo was working. In addition, neutral stimulus such as the color, taste, or smell of the supplement could have led to the association of taking an analgesic and enhancing the pharmacological effect of the supplement [27]. Research has shown that white placebo pills are perceived as analgesics and large capsules are perceived to offer stronger pharmacological effects [30]. In this investigation, the placebo pills contained powdered sugar in large capsules. The appearance of the placebo in this investigation could have led to the belief that they had the WWB and resulted in a perceived analgesic effect.

When collapsed across groups, there was a significant $(p<0.05)$ time difference for right mid-thigh pressure pain threshold with day three (72hrs) following resistance training and significantly lower than day six (post-supplementation). The pressure pain threshold for day three in the placebo group was $5.20 \%$ and $10.03 \%$ lower than the baseline measurements for the right and left mid-thigh, respectively. WWB partially eliminated the detrimental effects that inflammation and muscle damage had on pressure pain threshold. The average pressure pain threshold in the WWB was $1.71 \%$ and $3.69 \%$ lower than baseline during the peak of muscle soreness for the right and left mid-thigh, respectively. The results of the investigation revealed, while not statistically significant, WWB was superior to the placebo in maintaining pressure pain threshold. The data suggest that WWB has a potential to maintain pressure pain threshold following exercise.

In this investigation, thigh circumference was used to measure the acute inflammatory response following DOMS. Assessing circumference is often used in research to measure 
changes in inflammation over time [2,31,32]. Measurements of thigh circumference is an indicator of acute changes in the thigh volume due to inflammation associated with exercise induced muscle injury [32]. In the current investigation, the increase in mid-thigh circumference developed quickly following the cessation of exercise and continued to stay elevated. Thigh circumference was significantly higher immediately following exercise compared to both baseline and day-six (post-supplementation). The immediate inflammatory response resulting in the increase of thigh circumference is consistent with other studies that examined acute responses of DOMS on parameters of muscle damage [2,31,33]. During this six day study, both groups showed a similar pattern of declining inflammation following training. Due to no obvious differences between the two treatment conditions, the effect of WWB deceasing inflammation assessed by thigh circumference is inconclusive.

There were limitations that need to be considered in the present study. The primary limitation of the current study was the small sample size. It is speculated that increasing the sample size may have elicited significant differences between the groups regarding the subjective rating of muscle soreness or discomfort and the pressure pain threshold. A secondary limitation in the study is the lack of a control group. The placebo effect may have impacted the VAS scores and pressure pain threshold. The inclusion of a control group that did not take part in any treatment could bring more clarity on the analgesic effects of WWB by counteracting the placebo effect that may have occurred.

\section{Conclusion}

In this double-blind placebo-controlled study, the effects of WWB on the parameters of DOMS on apparent healthy adults was examined. After the five-day supplementation period following the induction of DOMS, there were no significant differences between the treatment conditions on any variable. Despite not being statistically significant, WWB decreased subjective pain and soreness evaluated by the VAS and preserved pressure pain threshold more than the placebo. Based on the findings, we believe WWB may offer some analgesic effects following a bout of exhaustive exercise as observed by the lower VAS scores and increased pressure pain threshold compared to the placebo. To confirm these results, future research will need to continue to study the analgesic and anti-inflammatory properties of WWB in non-clinical populations to determine if WWB would be a successful alternative to aspirin or other NSAIDs to treat DOMS following exercise.

\section{Conflicts of Interest}

The authors declare no conflict of interest.

\section{Acknowledgments}

The authors would like to thank the participants who volunteered their time to take part in this study.

\section{References}

1. Cheung K, Hume PA, Maxwell L. Delayed onset muscle soreness: Treatment strategies and performance factors. Sports Med. 2003; 33(2):145-164.

2. Manimmanakorn N, Manimmanakorn A, Boobphachart D, Thuwakum W, Laupattarakasem W, Hamlin MJ. Effects of Zingiber cassumunar (Plai cream) in the treatment of delayed onset muscle soreness. J Integr Med. 2016; 14(2):114-120.

3. Ranchordas MK, Rogerson D, Soltani H, Costello JT. Antioxidants for preventing and reducing muscle soreness after exercise: A Cochrane systematic review. Br J Sports Med. 2020; 54(2): 74-78.

4. Smith LL. Causes of delayed onset muscle soreness and the impact on athletic performance: A review. J Strength Cond Res. 1992; 6(3): 135-141.

5. Proske U, Morgan DL. Muscle damage from eccentric exercise: mechanism, mechanical signs, adaptation and clinical applications. J Physiol. 2001; 537(2): 333-345.

6. Davis JM, Murphy EA, Carmichael MD, et al. Curcumin effects on inflammation and performance recovery following eccentric exercise-induced muscle damage. Am J Physiol Regul Integr Comp Physiol. 2007; 292(6): 
R2168-R2173.

7. Viltrakyte E. Salicylates Amount Variation in Different Species of Lithuanian Willow [thesis]. [Kaunas]: Kaunas University of Medicine, Kaunas; 2008. 42 p.

8. Oketch-Rabah HA, Marles RJ, Jordan SA, Low Dog T. United States pharmacopeia safety review of willow bark. Planta Med. 2019; 85(16): 1192-1202.

9. Mahdi JG. Medicinal potential of willow: A chemical perspective of aspirin discovery. J Saudi Chem Soc. 2010; 14(3): 317-322.

10. European Medicines Agency (EMA). Assessment report on Salix [various species including S. purpurea L., S. daphnoides Vill., S. fragilis L.], cortex. n.d; https://www. ema.europa.eu/en/documents/herbal-report/finalassessment-report-salix-various-species-includings-purpurea-1-s-daphnoides-vill-s-fragilis-1_en.pdf. (Accessed Jan 10, 2021)

11. Biegert C, Wagner I, Lüdtke R, et al. Efficacy and safety of willow bark extract in the treatment of osteoarthritis and rheumatoid arthritis: Results of 2 randomized double-blind controlled trials. J Rheumatol. 2004; 31(11): 2121-2130.

12. Schmid B, Lüdtke R, Selbmann HK, et al. Efficacy and tolerability of a standardized willow bark extract in patients with osteoarthritis: Randomized placebocontrolled, double blind clinical trial. Phytotherapy Res. 2001; 15(4): 344-350.

13. Chrubasik S, Eisenberg E, Balan, E, Weinberger T, Luzzati $\mathrm{R}$, Conradt. Treatment of low back pain exacerbations with willow bark extract: A randomized double-blind study. Am J Med. 2000; 109(1): 9-14.

14. Chrubasik S, Künzel O, Black A, Conradt C, Kerschbaumer F. Potential economic impact of using a proprietary willow bark extract in outpatient treatment of low back pain: An open non-randomized study. Phytomedicine. 2001; 8(4): 241-251.

15. Chrubasik S, Künzel O, Model A, Conradt C, Black A. Treatment of low back pain with a herbal or synthetic anti-rheumatic: A randomized controlled study. Willow bark extract for low back pain. Rheumatology. 2001; 40(12): 1388-1393.
16. Uehleke B, Müller J, Stange, R, Kelber O, Melzer J. Willow bark extract STW 33-I in the long-term treatment of outpatients with rheumatic pain mainly osteoarthritis or back pain. Phytomedicine. 2013; 20(11): 980-984.

17. Beer AM, Wegener T. Willow bark extract (Salicis cortex) for gonarthrosis and coxarthrosis - results of a cohort study with a control group. Phytomedicine. 2008; 15(11); 907-913.

18. Saller R, Melzer J, Felder M. Pain relief with a proprietary extract of Willow Bark in Rheumatology. An open trial. Swiss J Integr Med. 2008; 20(3):156-162.

19. Purtian's Pride. Willow Bark 400mg. https://www.puritan. com/white-willow-bark-1230/white-willow-bark-400mg-000200. (Accessed Feb 10, 2019)

20. Selkow NM, Herman DC, Liu Z, Hertel J, Hart JM, Saliba SA. Blood flow after exercise-induced muscle damage. J Athl Train. 2015; 50(4): 400-406.

21. Kinser AM, Sands WA, Stone MH. Reliability and validity of a pressure algometer. J Strength Cond Res. 2009; 23(1): 312-314.

22. Waller R, Straker L, O’Sullivan P, Sterling M, Smith A. Reliability of pressure pain threshold testing in healthy pain free young adults. Scand J Pain. 2015; 9(1): 38-41.

23. Pumpa KL, Fallon KE, Bensoussan A, Papalia S. The effects of Panax notoginseng on delayed onset muscle soreness and muscle damage in well-trained males: A double blind randomized controlled trial. Complement Ther Med. 2013; 21(3): 131-140.

24. Wheeler AA, Jacobson BH. Effect of whole-body vibration on delayed onset muscular soreness, flexibility, and power. J Strength Conf Res. 2013; 27(9): 2527-2532.

25. Pen JL, Fisher C, Storzo AL, McManis GB. Cognitive strategies and pain tolerance in subjects with muscle soreness. J Sport Rehabil, 1995; 4:181-194.

26. Azevedo DC, Samulski DM. Assessment of psychological pain management techniques: A comparative study between athletes and non-athletes. Rev Bras de Medicina do Esporte 2003; 9(4): 214-222.

27. Colloca L. The placebo effect in pain therapies. Annu Rev Pharmacol Toxicol. 2019; 59(1); 191-211.

28. Carvalho C, Caetano JM, Cunha L, Rebouta P, Kaptchuk 
TJ, Kirsch I. Open-label placebo treatment in chronic low back pain: a randomized controlled trial. Pain. 2016; 157(12): 2766-2772.

29. Rossettini G, Carlino E, Testa M. Clinical relevance of contextual factors as triggers of placebo and nocebo effects in musculoskeletal pain. BMC Musculoskelet Disord. 2018; 19(27): 1-15.

30. Turner JA, Deyo RA, Loeser JD, Von Korff M, Fordyce WE. The importance of placebo effect in pain treatment and research. JAMA 1994; 271(20): 1609-1614.
31. Nosaka K, Clarkson P. Muscle damage following repeated bouts of high force eccentric exercise. Med Sci Sports Exerc. 1995; 27(9): 1263-1269.

32. Nosaka K, Clarkson PM. Changes in indicators of inflammation after eccentric exercise of the elbow flexors. Med Sci Sports Exerc.1996; 28(8): 953-961.

33. Tanabe Y, Maeda S, Akazawa N, et al. Attenuation of indirect markers of eccentric exercise-induced muscle damage by curcumin. Eur J Appl Physiol. 2015; 115(9): 949-1957. 